\title{
Welcome address
}

\author{
Christine Deschamps \\ President, International Federation of Library Associations and Institutions (IFLA), P.O. Box 95312, \\ 2509 CH, The Hague, The Netherlands
}

Ladies and gentlemen, it is a great pleasure for me to open this conference. Our first speaker is Mr. Bernard Bigot, Head of Cabinet at the Ministry for Research and New Technology. It is important to underline the efforts of the Ministry in the field of Science and Information and the use of new technologies. His presence this morning demonstrates the Ministry's interest in our cause.

\section{Bernard Bigot}

Head of Cabinet, Ministry Delegate for Research \& New Technology, France

Ladies and Gentlemen, I feel greatly honoured to welcome you to this important seminar. I am pleased to see so many people in attendance. This shows the significance of the topics you will debate during these two days. At the Ministry Delegate for Research and New Technology, which is committed to progress of knowledge in the technical and scientific domains, we are conscious of the increasing influence of scientific and technical information policies on this progress, as is the Ministry of Youth, Education and Research, which we are part of.

We are all confronted with difficult issues. The existing economic models for publishing are being challenged by the technological changes taking place in the world. Scientific information is produced by the research community, and the publishers' responsibility has always been to ensure dissemination of this work by offering high-quality peer reviewed journals and related services. The proper functioning of these mechanisms relies on a kind of financial equilibrium. At present however, they are affected by costs which are becoming out of control. With subscription costs increasing by 5 to $15 \%$ per year, no research organisation can accept this trend. Equally, the government cannot increase its budget in the same proportions. In this situation, paradoxically, choices of subscriptions made by academic institutions are founded more on economic necessity than scientific rationale.

In this respect, by reducing the cost of printing and mailing, new technology can represent a potential solution, by giving at the same time added value to the information products. We are aware of the numerous initiatives aiming to set up alternative publication models. However, we also understand that there is much concern in the scientific community.

Consequently, we hope that this meeting can explore the best ways of distributing information in a way to benefit all. In this regard, I would like to confirm that the Minister is aware of the challenge and is paying close attention to the results of your work. Toward this end, we all have responsibilities and, on behalf of the Ministry, I hope your work will be fruitful. 